\title{
Zhenju Jiangya Tablet-induced Acute Kidney Injury: A Case Report and Literature Review \\ $\mathrm{B} \mathrm{Li}^{1}, \mathrm{Q} \mathrm{Wen}^{2}, \mathrm{Z} \mathrm{Gao}^{1}, \mathrm{Z} \mathrm{Hu}^{1}, \mathrm{X} \mathrm{Yang}^{1}, \mathrm{~T} \mathrm{Peng}^{1}$
}

\section{INTRODUCTION}

Zhenju Jiangya tablet is used to control hypertension, and it is composed by traditional Chinese medicines. Weight of each piece is $0.26 \mathrm{~g}$. It is dangerous for patients allergic to hydrochlorothiazide, clonidine and sulfa drugs; it is also banned from pregnant women, lactating women. There is no adverse reaction in most patient who accept the Zhenju Jiangya tablet, and few patients has following symptoms: dry mouth, polyuria, fatigue. After application with Zhenju Jiangya tablet, the worst adverse reactions are photosensitivity dermatitis, drug eruption, electrolyte balance disorders and acute gouty arthritis. There are reports cases on elevated blood glucose, but no reports on acute kidney injury (AKI). We reported an episode of AKI associated with Zhenju Jiangya tablet use and discussed this topic in medical literature. Zhenju Jiangya tablet-induced AKI is rare. The mechanism and pathogenesis of Zhenju Jiangya tablet-induced AKI remains unknown. The aim of the present report is to remind most of the medical workers, especially the grassroots medical workers to concern about this drug and the disease.

Keywords: Acute kidney injury, adverse reaction, Zhenju Jiangya tablet

From: ${ }^{1}$ Department of Nephrology, Shandong University Qilu Hospital Qingdao District, and ${ }^{2}$ Department of Internal Medicine, Invalides General Hospital of Shandong Province, China.

Correspondence: Dr T Peng, Department of Nephrology, Shandong University Qilu Hospital, Jinan 250012, China. Phone: 86-531-8216-936; E-mail: sesame_oil@126.com 


\section{CASE REPORT}

A 45-year-old male was admitted to Shandong University Qilu hospital with AKI. He had a history of a fever, the highest body temperature was $39.5^{\circ} \mathrm{C}$, with chills, head and face congestive rash, itching throughout the body after taking Zhenju Jiangya tablet. In local hospital, though azithromycin, cephalosporins, ribavirin, dexamethasone were given, there was not any effect. Symptoms of the patient included edema in lower extremity, anuria, body rash, desquamation, and eosinophils increasing up to $33.4 \%$. Serum creatinine increased from normal to $816 \mu \mathrm{mol} / \mathrm{L}$, and he was admitted to department of nephrology, Shandong University Qilu hospital on February 21, 2012.

The patient had a history of hypertension with 5 years, fluctuating from 190/125 to 140/80 $\mathrm{mmHg}$, and not history of diabetes, coronary heart disease, drug allergy, blood transfusion, smoking and drinking.

At the time of admission, his blood pressure (BP) was 136/84 mmHg, heart rate was 63 per minute and body temperature was $36.7^{\circ} \mathrm{C}$. Physical examination showed dry skin throughout the body, congestive rash, and facial visible desquamation. Double eyelids were edema, lung breath sounded thick, a small amount of wet and dry rales can be heard. On adimission, his hemoglobin (Hgb) was $100.4 \mathrm{~g} / \mathrm{L}$, blood urine nitrogen (BUN) was 12.4 $\mathrm{mmol} / \mathrm{L}$, and serum creatinine (SCr) was $399.30 \mu \mathrm{mol} / \mathrm{L}$. His C-reactive protein (CRP) was $28.4 \mathrm{mg} / \mathrm{L}$. Anti-glomerular basement memerbrous antibody, anti-double strain antiboby, anti-nuclear antibody, prothrombin time, completement 3 , and completement 4 were normal. Perinuclear and cytoplasmic anti-neutrophil cytoplasmic antibody (P-ANCA and C-ANCA) were normal. Alanine aminotransferase was $78 \mathrm{U} / \mathrm{L}$, glutamyl transferase was $344 \mathrm{U} / \mathrm{L}$, but 
aspartate aminotransferase and lactate dhydrogensase were normal. The number of white blood cell (WBC) was $18.75 \times 10^{9} / \mathrm{L}$ and the ratio of eosinophilic granulocytes to total WBC was $33.4 \%$.

Primary diagnosis:

(1) Eosinophil cell histiocytosis?

(2) Acute kidney injury?

(3) Hypertension

After admission, he underwent bone marrow biopsy immediately, which result showed eosinophils was normal in bone marrow. Immunoglobulin E (I.e.) was $4190 \mathrm{IU} / \mathrm{ml}$ (0 100), CRP was $33.8 \mathrm{mg} / \mathrm{L}(0 \sim 8), \beta_{2}$-microglobulin $\left(\beta_{2}-\mathrm{M}\right)$ was $21.1 \mathrm{mg} / \mathrm{L}(0.7 \sim 1.8)$, alanine aminotransferase(ALT) was $26 \mathrm{U} / \mathrm{L}$, gamma-glutamyl trans peptidase(GGT) was $97 \mathrm{U} / \mathrm{L}$, BUN $21.35 \mathrm{mmol} / \mathrm{L}, \mathrm{SCr}$ was $816 \mathrm{umol} / \mathrm{L}$, uric acid(UA) was 577umol/L, $\mathrm{CO}_{2}-\mathrm{CP}$ was 16.3 $\mathrm{mmol} / \mathrm{L}, \mathrm{Ca}^{2+}$ was $1.82 \mathrm{mmol} / \mathrm{L}$ and lactate dehydrogenase(LDH) was $409 \mathrm{U} / \mathrm{L}$ in his serum. The size of both kidneys were normal. Cortex and medulla were all clear. No caliectasis, pyelectasis and obvious dilatation were found. His electrocardiogram was normal. In his urine, immunoglobulin $\mathrm{G}$ (IgG) was $7.76 \mathrm{mg} / \mathrm{L}$, albumin (Alb) was $23.60 \mathrm{mg} / \mathrm{L}$, $\alpha_{1}$-microglobulin $\left(\alpha_{1}-\mathrm{M}\right)$ was $83.50 \mathrm{mg} / \mathrm{L}$, and $\beta_{2}-\mathrm{M}$ was $28.00 \mathrm{mg} / \mathrm{L}$

According to the typical clinical manifestations, medical history and laboratory tests, diagnosis of drug-induced AKI (acute interstitial nephritis) was established. The patient refused to accept the renal biopsy, renal pathological data did not exist.

The study protocol was approved by the ethics committee of the hospital, and written informed consent was obtained from patient after he had reviewed a written summary of the 
study plan.

\section{Clinical treatment}

Volume of urine increased from 100 to $500 \mathrm{ml} / 24$ hours and $\mathrm{SCr}$ decreased from 816 to 509 $\mu \mathrm{mol} / \mathrm{L}$ two days after hemodialysis and other measures immediately. When volume of urine increased to $1200 \mathrm{ml} / 24$ hours, hemodialysis stopped. On the twelfth and fourteenth day of admission, volume of urine and Scr were $2100 \mathrm{ml} / 24$ hours and $107 \mu \mathrm{mol} / \mathrm{L}, 2800 \mathrm{ml} / 24$ hours and $87 \mu \mathrm{mol} / \mathrm{L}$, respectively. Rash and welling disappeared. His Hgb, WBC and eosinophils in blood were normal. GGT, ALT and other blood biochemical indices were also normal.

\section{DISCUSSION}

Zhenju Jiangya tablet is commonly used in clinical anti-hypertension. There is a good effect in primary hypertension. Some adverse reactions were seen in a few people, for example, photosensitive dermatitis, drug eruption, electrolyte imbalance, allergic rash, acute gouty arthritis and elevated blood glucose (1-4). But so far, there was not any report on Zhenju Jiangya tablet-induced AKI.

Characteristics of the case: 1 . The patient had the history of Zhenju Jiangya tablet application with head and face congestive rash, itching throughout the body. 2 . The clinical manifestations of AKI came out shortly after the drug application and the serum creatinine raised sharply within a short time. Urine output dramatically reduced. 3. By withdrawal of the drug and treatment, the renal function of the patient rapidly returned to normal. In summary, 
the diagnosis of drug-induced AKI was clear, and the history of drug application, laboratory renal tests and response to treatment were the key of diagnosis.

Because of some unknown causes, the patient did not undergo renal pathology in early onset of the drug-induced AKI in other hospital. After admission into our department, because a clear diagnosis was established based on clinical manifestations, laboratory renal tests and response to treatment, the families of the patient refused to accept the kidney biopsy.

Acute interstitial nephritis caused by drug allergy is the immune response. Clinical symptoms and exposure to drugs are always uncertain (5-8). General condition, the extent and amount of kidney damage, the severity are also different (9.10). The symptoms of acute renal dysfunction, $20 \%$ of cases with oliguria, are accompanied by unexplained fever, rash, joint pain, swollen lymph nodes and other allergic symptoms after drug application. Blood eosinophils was significantly increased by $80 \%$ of visible blood in some cases with elevated immunoglobulin $\operatorname{IgE}(11,12)$. To stop the allergy drug with adrenal cortex hormone therapy is an important step, and after a few weeks, renal function gradually returned to normal. The key is early diagnosis, timely withdrawal the drug $(13,14)$.

Kidney is the organ of excretion of water-soluble substances. After the tubular reabsorption of $99 \%$ moisture, water-soluble drugs or their metabolites are not re-absorpted. Because urine concentrations is up to 100 times than plasma concentration, water-soluble drugs or metabolites easily lead to kidney damage (15). Risk factors affecting drug-induced renal impairment include: old age, dehydration and underlying kidney disease, high blood pressure, serum electrolyte abnormalities, heart failure and liver function disorders.

Renal blood flow volume is about $1 / 4$ of stroke volume, and the amount of the drug 
through kidney is relatively more than the other organs. Because of renal tubular secretion and re-absorption of drugs, concentration of drug in the kidney is very high, especially the renal medulla and papilla, which are prone to be damage because of significantly increased drug concentration by countercurrent multiplication mechanism. The tubular acidification process, which can affect the solubility of certain drugs, are prone to drug deposition. Antigen-antibody immune complex are prone to deposit in the kidney because of rich renal capillaries. All above mentioned cause easily drug-induced renal injury.

The ways of Chinese medicine causing renal damage (16-18): 1. Overdose or inappropriate dose leads to kidney damage. 2. Toxins in Chinese medicine lead to tubular or renal vascular injury, and subsequent renal interstitial inflammation and fibrosis. 3. Medicine cause systemic allergicreaction, causing acute allergic interstitial nephritis.

Now, the mechanism of Zhenju Jiangya tablet-induced AKI is unclear, which might be similar to the mechanism of other drug-induced AKI. It perhaps related to acute interstitial nephritis caused by drug allergy. The clinical signs and laboratory tests confirmed that the patient's own humoral immunity was involved in the pathogenesis of AKI, so glucocorticoids application, microcirculation improvement, sufficient energy given, and symptomatic supportive treatment are conducive to eventually recovery.

\section{CONCLUSIONS}

Zhenju Jiangya tablet-induced AKI is rare. The mechanism and pathogenesis of Zhenju Jiangya tablet-induced AKI remains unknown. The aim of the present report is to remind 
most of the medical workers, especially the grassroots medical workers to concern about this drug and the disease.

\section{AUTHORS NOTE}

The authors declare that they have no competing interests. No funding was involved.

\section{Authors' contributions}

Tao Peng and Bing Li participated in the design of the study and performed the statistical analysis. Bing Li drafted the manuscript. Xiangdong Yang, Zhao $\mathrm{Hu}$ and Zhaoli Gao participated in its design and coordination and helped to draft the manuscript. All authors read and approved the final manuscript. 


\section{REFERENCES}

1. Hoe KK. Blood pressure and the natural diets: more to learn. West Indian Med J $2014 ; 63: 283-4$.

2. Ma WJ, Tang JL, Zhang YH, Xu YJ, Lin JY, Li JS, Lao XQ, Tam WW, Wong MC, Yu IT. Hypertension prevalence, awareness, treatment, control, and associated factors in adults in southern China. Am J Hypertens 2012; 25: 590-6.

3. Liu LS. Writing Group of 2010 Chinese Guidelines for the Management of Hypertension. 2010 Chinese guidelines for the management of hypertension. Zhonghua Xin Xue Guan Bing Za Zhi. 2011; 39: 579-615.

4. Hou XM, Ni HC, Luo XP, Shi HM, Fan WH. Effect of Zhenju Jiangya Tablet on the endothelial function of hyperlipidemic rabbits. Zhong Xi Yi Jie He Xue Bao. 2004; 2 2: $111-4$.

5. Whitman CB, Wike MJ. Possible case of nafcillin-induced acute interstitial nephritis. Am J Health Syst Pharm 2012; 69: 1049-53.

6. Peng T, Gao H, Shen L, Xu F, Yang X. Correlation of brain natriuretic peptide and microalbuminuria in patients with heart failure. West Indian Med J 2011; 60: 658-61.

7. Chen D, Luo C, Tang Z, Zhou Y, Chen H, Zeng C, Liu Z. Delayed renal function recovery from drug-induced acute interstitial nephritis. Am J Med Sci 2012; 343: $36-9$.

8. Galesić K, Prkacin I, Tisljar M, Horvatić I, Ljubanović DG. Drug induced allergic interstitial nephritis. Lijec Vjesn 2011; 133: 276-83. 
9. Zheng J, Xiao Y, Chong M, Chen Y, Yao Y, Jin M, Liu Y, Han L. The effect of cardiopulmonary bypass duration on renal injury after congenital heart surgery in infants and young children. Adv Clin Exp Med 2013; 22: 693-8.

10. Kaakeh Y, Kanjee S, Boone K, Sutton J. Liraglutide-induced acute kidney injury. Pharmacotherapy. 2012; 32: e7-11.

11. Chen YP. Experiences on the integrative medical diagnosis and treatment of acute kidney injury. Chin J Integr Med 2010; 16: 207-12.

12. Hsu WH, Ho TJ, Huang CY, Ho HC, Liu YL, Liu HJ, Lai NS, Lin JG. Chinese medicine acupoint herbal patching for allergic rhinitis: a randomized controlled clinical trial. Am J Chin Med 2010; 38: 661-73.

13. Bentley ML, Corwin HL, Dasta J. Drug-induced acute kidney injury in the critically ill adult: recognition and prevention strategies. Crit Care Med 2010; 38: S169-74.

14. Melchart D, Linde K, Hager S, Kaesmayr J, Shaw D, Bauer R, Weidenhammer W. Monitoring of liver enzymes in patients treated with traditional Chinese drugs.Complement Ther Med 1999; 7: 208-16.

15. Brenner and Rector's The Kidney, 9th ed. - 2011 - Saunders, An Imprint of Elsevier.

16. Sheng B, He D, Zhao J, Chen X, Nan X. The protective effects of the traditional Chinese herbs against renal damage induced by extracorporeal shock wave lithotripsy: a clinical study. Urol Res 2011; 39: 89-97.

17. Shin S, Lee YJ, Kim EJ, Lee AS, Kang DG, Lee HS. Effect of Cuscuta chinensis on renal function in ischemia/reperfusion-induced acute renal failure rats. Am J Chin Med. 2011; 39: 889-902. 
18. Isnard Bagnis C, Deray G, Baumelou A, Le Quintrec M, Vanherweghem JL. Herbs and the kidney. Am J Kidney Dis 2004; 44: 1-11. 